\title{
Editorial
}

\section{Palavras do Prof. Fabio B. Jatene}

Chega ao fim meu mandato como editor da Revista Brasileira de Cirurgia Cardiovascular. Foram seis anos de trabalho intenso e às vezes difícil, mas muito gratificante, com várias conquistas para a RBCCV.

Assim, quero aproveitar este número da Revista para agradecer todo o apoio recebido ao longo da gestão. Diretorias da SBCCV, Editores Associados, Conselho Editorial, Equipe Administrativa, Autores, Anunciantes, Leitores, todos tiveram um importante papel para garantir o aperfeiçoamento de nossa Revista. Gostaria de ressaltar e agradecer nominalmente a algumas pessoas: inicialmente, aos professores Geraldo Verginelli, Luís Alberto Dallan, Pablo Pomerantzeff, companheiros incansáveis ao longo desses anos; à Rosangela Monteiro, assessora editorial, por sua enorme capacidade de trabalho e organização, e à Márcia Silvana, secretária, pela sua dedicação à
RBCCV. Por fim, um agradecimento muito especial e carinhoso à Lylian de Vasconcellos, editora executiva, que não poupou esforços para garantir que nossa Revista continuasse evoluindo, que depositou não apenas conhecimento técnico-científico profissional, mas, principalmente, amor e dedicação.

Poderia enumerar algumas conquistas obtidas durante nossa gestão, como a internacionalização das normas da Revista, a parceria com o The Heart Surgery Forum, a versão eletrônica - Internet - com incorporação e indexação no projeto SciELO, a obtenção de recursos junto às agências de fomento à pesquisa (FAPESP e CNPq) e, principalmente, a instituição da arbitragem dos trabalhos científicos submetidos para publicação em nossa Revista. Todas as principais revistas do mundo utilizam esta prática que está sendo hoje rotineira para nós. 
Foram passos importantes, que podem, talvez, ter sido despercebidos a muitos, mas que só foram possíveis graças ao esforço e carinho de todos. Sem dúvida, muitas outras conquistas virão em breve, fazendo a RBCCV crescer cada vez mais, permitindo que ela cumpra seu papel na divulgação do conhecimento científico produzido em nossa Sociedade e na formação e aprimoramento de nossos associados.

Fabio B. Jatene Editor- RBCCV 